\title{
$\beta \bigvee$-tubulin expression is associated with outcome following taxane-based chemotherapy in non-small cell lung cancer
}

\author{
DC Christoph ${ }^{*, 1,2}$, S Kasper', TC Gauler ${ }^{1,3}$, C Loesch $^{4}$, M Engelhard ${ }^{5}$, D Theegarten ${ }^{6}$, C Poettgen $^{5}$, R Hepp $^{5}$, \\ A Peglow ${ }^{6}$, H Loewendick', S Welter ${ }^{7}$, G Stamatis' ${ }^{7}$, FR Hirsch ${ }^{2,8}$, M Schuler ${ }^{1,3}$, WEE Eberhardt ${ }^{1,3}$ \\ and J Wohlschlaeger ${ }^{6}$
}

'Department of Medical Oncology, West German Cancer Centre, University Hospital Essen, University Duisburg-Essen, Hufelandstrasse 55, Essen 45 147, Germany; ${ }^{2}$ Department of Medicine, Division of Medical Oncology, University of Colorado Denver, Aurora, CO 80045, USA; ${ }^{3}$ Division of Thoracic Oncology, Ruhrlandklinik, University Duisburg-Essen, Essen 45239, Germany; ${ }^{4}$ Institute for Medical Informatics, Biometry and Epidemiology, West German Cancer Centre, University Hospital Essen, University Duisburg-Essen, Essen 45I 47, Germany; ${ }^{5}$ Department of Radiotherapy, West German Cancer Centre, University Hospital Essen, University Duisburg-Essen, Essen 45147, Germany; ${ }^{6}$ Department of Pathology and Neuropathology, West German Cancer Centre, University Hospital Essen, University Duisburg-Essen, Essen 45/47, Germany; ${ }^{7}$ Division of Thoracic Surgery and Endoscopy, Ruhrlandklinik, University Duisburg-Essen, Essen 45239, Germany; ${ }^{8}$ Department of Pathology, University of Colorado Denver, Aurora, CO 80045, USA

BACKGROUND: Tubulin-binding agents (TBAs) are effective in non-small cell lung cancer (NSCLC) treatment. Both $\beta \| I$ - and $\beta$ V-tubulins are expressed by cancer cells and may lead to resistance against TBAs.

METHODS: Pre-treatment samples from 65 locally advanced or oligometastatic NSCLC patients, who underwent uniform induction chemotherapy with paclitaxel and platinum followed by radiochemotherapy with vinorelbine and platinum were retrospectively analysed by immunohistochemistry. Protein expression of $\beta \| I-$ and $\beta \bigvee$-tubulin was morphometrically quantified.

RESULTS: Median pre-treatment $H$-score for $\beta$ Ill-tubulin was IIO (range: 0-290), and I60 for $\beta \bigvee$-tubulin (range: 0-290). Low $\beta$ III-tubulin expression was associated with improved overall survival (OS) $(P=0.0127$, hazard ratio (HR): 0.328$)$. An association between high $\beta \bigvee$-tubulin expression and prolonged progression-free survival (PFS, median 19.2 vs 9.4 months in high vs low expressors; $P=0.0315$, HR: 1.899) was found. Further, high $\beta \bigvee$-tubulin expression was associated with objective response (median $\mathrm{H}$-score 172.5 for $\mathrm{CR}+\mathrm{PR}$ vs 120 for $\mathrm{SD}+\mathrm{PD}$ patients, $P=0.0104$ ) or disease control following induction chemotherapy ( 170 for $C R+P R+S D$ vs 100 for $P D$ patients, $P=0.008 I$ ), but not radiochemotherapy.

CONCLUSION: Expression of $\beta \bigvee$-tubulin was associated with treatment response and PFS following paclitaxel-based chemotherapy of locally advanced and oligometastatic NSCLC patients. Prolonged OS was associated with low levels of $\beta$ III-tubulin. Prospective evaluation of $\beta \| 1 / / \beta \bigvee$-tubulin expression in NSCLC is warranted.

British Journal of Cancer (2012) 107, 823-830. doi:I0.1038/bjc.2012.324 www.bjcancer.com

Published online 26 July 2012

(c) 2012 Cancer Research UK

Keywords: non-small cell lung cancer; biomarker; $\beta \| I I-/ \beta \bigvee$-tubulin; paclitaxel; vinorelbine

Multimodality treatment is an accepted standard for optimal management of patients with locally advanced non-small cell lung cancer (NSCLC). In particular, induction chemotherapy followed by combined radiochemotherapy and/or surgical resection is highly effective and potentially curative in selected stage III patients (Felip and Vilar, 2006; Kang et al, 2010). Definitive radiochemotherapy after induction chemotherapy is a recommended treatment strategy for locally advanced, inoperable stage IIIA/B NSCLC patients (Azuma et al, 2009a). Tubulin-binding agents (TBAs) such as taxanes and Vinca alkaloids act by impairing the normal function of mitotic spindles. Microtubules

\footnotetext{
*Correspondence: Dr DC Christoph; E-mail: daniel.christoph@uk-essen.de This work was presented in part at the 14th World Conference on Lung Cancer, Amsterdam, The Netherlands, 3-7 July 201 I (Poster Session 2; abstract no. 2.227) and at the EORTC-NCl-ASCO Annual Meeting on 'Molecular Markers in Cancer', Brussels, Belgium, 27-29 October 20I I (Poster Viewing Session, abstract ld 35).

Revised 28 May 2012; accepted 30 May 2012; published online 26 July 2012
}

are composed of $\alpha \beta$-dimers and form the fibres of the mitotic spindle. TBAs target microtubules and change their polymerisation or depolymerisation dynamics, ultimately leading to mitotic arrest and cell death (Jordan, 2002). Paclitaxel binds to $\beta$-tubulin that leads to tubulin polymerisation, microtubule stabilisation (Orr et al, 2003), and inhibition of microtubule disassembly in cancer cells (Jordan and Wilson, 2004).

The eight members of the $\beta$-tubulin gene family produce homologous proteins that differ most notably in the last 15-20 C-terminal amino acids (Banerjee et al, 2008; Bhattacharya and Cabral, 2009). These carboxyl-terminal sequences have been used to assign $\beta$-tubulin gene products to eight distinct classes. Each of these classes (referred to as $\beta \mathrm{I}, \beta \mathrm{II}, \beta \mathrm{III}, \beta \mathrm{IVa}, \beta \mathrm{IVb}, \beta \mathrm{V}, \beta \mathrm{VI}$, and $\beta$ VII) defines a $\beta$-tubulin isotype that differs significantly from other isotypes within the same organism, but is highly conserved between other vertebrate species (Bhattacharya and Cabral, 2004). Murine and human $\beta$ III- or $\beta \mathrm{V}$-tubulin display 99.8 or $97.7 \%$ sequence identity and human $\beta \mathrm{V}$-tubulin differs mainly at the last two C-terminal amino-acid residues from the corresponding rodent residues (Verdier-Pinard et al, 2005). 
Disregarding $\beta$ VI- and $\beta$ VII-tubulin, $\beta$-tubulin isotypes fall into two distinct evolutionary branches consisting of $\beta \mathrm{I}^{-}, \beta \mathrm{II}-$, and $\beta \mathrm{IV}$-tubulin on the one hand, and $\beta \mathrm{III}-$ and $\beta \mathrm{V}$-tubulin on the other (Verdier-Pinard et al, 2005). One striking difference between the tubulin isotypes $\beta \mathrm{III}$ and $\beta \mathrm{V}$ is that the latter is found in glia and not in neurons (except some ganglion cells), whereas $\beta$ III-tubulin is found in neurons and not in glia (Sullivan et al, 1986; Verdier-Pinard et al, 2005). Both of these isotypes are expressed in cancer cells, although their patterns of expression seem to be reciprocal (low $\beta$ III-tubulin/high $\beta \mathrm{V}$-tubulin and vice versa) (Verdier-Pinard et al, 2005; Hiser et al, 2006). Recently, $\beta \mathrm{V}$-tubulin expression was found to predict poor outcome in colorectal cancer patients and gender might influence the predictive value of $\beta \mathrm{III}-/ \beta \mathrm{V}$-tubulin expression (Mariani et al, 2012).

Overexpression of $\beta$ III-tubulin moderately destabilised microtubules in cells that were weakly paclitaxel resistant (Hari et al, 2003), and reduced the ability of paclitaxel to suppress microtubule dynamics (Kamath et al, 2005). BIII-tubulin expression in cancer cells or primary tumours was correlated with a decreased sensitivity to paclitaxel (Orr et al, 2003). Several studies reported a correlation between low or absent intratumoural $\beta$ III-tubulin expression and improved objective response (OR) (Seve et al, 2005; Zalcman et al, 2009), as well as prolonged progression-free survival (PFS) (Dumontet et al, 2005; Seve et al, 2005; Zalcman et al, 2009; Azuma et al, 2009b) in paclitaxel-treated patients with locally advanced or metastatic NSCLC. However, contradictory results have also been reported (Rosell et al, 2003; Azuma et al, 2009a; Kang et al, 2009). Equally contradictory reports have been published regarding the association of $\beta$ III-tubulin expression with overall survival (OS) (Dumontet et al, 2005; Seve et al, 2005; Okuda et al, 2008; Azuma et al, 2009a, 2009b; Kang et al, 2009; Zalcman et al, 2009). In contrast, $\beta \mathrm{V}$-tubulin has received less attention despite its similarity to $\beta$ III-tubulin, which also suggests a possible interaction with TBAs (Banerjee et al, 2008).

We hypothesised that combined analysis of $\beta \mathrm{III}$ - and $\beta \mathrm{V}$-tubulin protein expression may result in an improved predictive biomarker for NSCLC patients undergoing taxane-based chemotherapy. At the initiation of this study there was no anti-human $\beta \mathrm{V}$-tubulin antibody available, which was tested for immunohistochemistry (IHC). Therefore, we established and validated a $\beta \mathrm{V}$-tubulin assay.

\section{MATERIALS AND METHODS}

\section{Patients}

This retrospective study examined pre-treatment tumour samples from 65 patients treated at a single comprehensive cancer centre (West German Cancer Centre, University Hospital Essen, Essen, Germany), who were diagnosed between July 2003 and January 2010. Paclitaxel-based induction treatment was initiated between May 2004 and January 2010. Locally advanced NSCLC patients with histopathologically (by bronchoscopy and mediastinoscopy) proven stage IIIA (N2), and selected patients with stage IIIB or oligometastatic stage IV (single metastasis, e.g., in adrenal glands) were included. None of the patients had received prior chemotherapy. Detailed clinicopathological and epidemiological characteristics (Table 1) were obtained via chart review conducted by an independent investigator, who was blinded to the results of the immunohistochemical analysis. Clinical and pathological tumour stages were classified according to the seventh edition of the tumour-node-metastasis system, which is recommended by the International Association for the Study of Lung Cancer (IASLC) (Detterbeck et al, 2009). Tumour histology was classified based on World Health Organisation criteria. Analysis of tumour samples and clinical data was consented by all alive patients; the study was
Table I Clinicopathological data of investigated NSCLC patients

\begin{tabular}{|c|c|}
\hline Characteristics & $\begin{array}{l}\text { Number of } \\
\text { patients (\%) }\end{array}$ \\
\hline Number of patients (\%) & $65(100 \%)$ \\
\hline $\begin{array}{l}\text { Age } \\
\text { Median age at diagnosis in years (range) }\end{array}$ & $53(35-70)$ \\
\hline $\begin{array}{l}\text { Gender } \\
\text { Female } \\
\text { Male }\end{array}$ & $\begin{array}{l}21(32 \%) \\
44(68 \%)\end{array}$ \\
\hline $\begin{array}{l}\text { Side } \\
\text { Left } \\
\text { Right }\end{array}$ & $\begin{array}{l}24(37 \%) \\
41(63 \%)\end{array}$ \\
\hline $\begin{array}{l}\text { T stage } \\
\text { T1 } \\
\text { T2 } \\
\text { T3 } \\
\text { T4 }\end{array}$ & $\begin{array}{l}3(5 \%) \\
16(25 \%) \\
16(25 \%) \\
30(46 \%)\end{array}$ \\
\hline $\begin{array}{l}N \text { stage } \\
\text { No } \\
\text { N1 } \\
\text { N2 } \\
\text { N3 }\end{array}$ & $\begin{aligned} & 15(23 \%) \\
& 5(8 \%) \\
& 27(42 \%) \\
& 18(28 \%)\end{aligned}$ \\
\hline $\begin{array}{c}M \text { stage } \\
\text { MO } \\
\text { MI }\end{array}$ & $\begin{array}{l}55(85 \%) \\
10(15 \%)\end{array}$ \\
\hline $\begin{array}{l}\text { IASLC stage (at diagnosis) } \\
\text { I } \\
\text { II } \\
\text { III } \\
\text { IV }\end{array}$ & $\begin{array}{c}2(3 \%) \\
1(2 \%) \\
52(80 \%) \\
10(15 \%)\end{array}$ \\
\hline $\begin{array}{l}\text { Histologic subtype } \\
\text { Adenocarcinoma } \\
\text { Squamous cell carcinoma } \\
\text { Large cell carcinoma } \\
\text { Other tumours and mixed tumours }\end{array}$ & $\begin{array}{r}29(45 \%) \\
16(25 \%) \\
6(10 \%) \\
14(22 \%)\end{array}$ \\
\hline $\begin{array}{l}\text { Grading } \\
\text { G2 } \\
\text { G3 } \\
\text { G4 }\end{array}$ & $\begin{array}{c}19(29 \%) \\
42(65 \%) \\
4(6 \%)\end{array}$ \\
\hline $\begin{array}{l}\text { Induction chemotherapy } \\
\text { Cisplatin plus paclitaxel } \\
\text { Carboplatin plus paclitaxel } \\
\text { Median number of cycles (range) } \\
\text { Median cumulative paclitaxel dose in mg (range) }\end{array}$ & $\begin{aligned} & 63(97 \%) \\
& 2(3 \%) \\
& 3(2-4) \\
& 990(560-1400)\end{aligned}$ \\
\hline $\begin{array}{l}\text { Combined radiochemotherapy } \\
\text { Cisplatin plus vinorelbine } \\
\text { Carboplatin plus vinorelbine } \\
\text { Cisplatin } \\
\text { No concomitant chemotherapy } \\
\text { Median cumulative radiotherapy dose (in Gy; range) }\end{array}$ & $\begin{array}{l}50(77 \%) \\
2(3 \%) \\
3(5 \%) \\
10(15 \%) \\
46(30-71.6)\end{array}$ \\
\hline $\begin{array}{l}\text { Response to induction chemotherapy } \\
\text { CR } \\
\text { PR } \\
\text { SD } \\
\text { PD }\end{array}$ & $\begin{aligned} 1 & (2 \%) \\
45 & (69 \%) \\
12 & (18 \%) \\
7 & (11 \%)\end{aligned}$ \\
\hline $\begin{array}{l}\text { Response to induction chemotherapy (only IASLC stage III patients) } \\
\text { CR } \\
\text { PR } \\
\text { SD } \\
\text { PD }\end{array}$ & $\begin{aligned} 52 & (100 \%) \\
1 & (2 \%) \\
38 & (73 \%) \\
10 & (19 \%) \\
3 & (6 \%)\end{aligned}$ \\
\hline $\begin{array}{l}\text { Response to induction chemotherapy (only IASLC stage IV patients) } \\
\text { PR } \\
\text { PD }\end{array}$ & $\begin{array}{l}10(100 \%) \\
6(60 \%) \\
4(40 \%)\end{array}$ \\
\hline $\begin{array}{l}\text { Response to combined radiochemotherapy } \\
\text { CR } \\
\text { PR } \\
\text { SD } \\
\text { PD }\end{array}$ & $\begin{array}{l}2(3 \%) \\
31(48 \%) \\
30(46 \%) \\
2(3 \%)\end{array}$ \\
\hline $\begin{array}{l}\text { Survival } \\
\quad \text { Median PFS in months (range) } \\
\text { Median OS in months ( range) }\end{array}$ & $\begin{array}{l}14.1(0.9-62.1) \\
59.3(2.1-74.0)\end{array}$ \\
\hline
\end{tabular}

Abbreviations: $C R=$ complete remission; $\mid \mathrm{ASLC}=$ International Association for the Study of Lung Cancer; NSCLC = non-small cell lung cancer; OS = overall survival; $\mathrm{PD}=$ progressive disease; $\mathrm{PFS}=$ progression-free survival; $\mathrm{PR}=$ partial remission; $\mathrm{SD}=$ stable diseasel. Note that percentages may not total 100 because of rounding. 
approved by the Ethics Committee of the Medical Faculty of the University Duisburg-Essen (no. 10-4404).

\section{Treatment}

Patients received (Figure 1: flowchart of patients' treatment) induction chemotherapy (CTX) followed by radiochemotherapy consisting of hyperfractionated radiotherapy and chemotherapy. If technically and functionally feasible and restaging showed no progression, patients underwent surgery 3-5 weeks after the end of radiochemotherapy. In patients deemed inoperable at the end of radiochemotherapy or with comorbidities excluding operation, a definitive boost of radiochemotherapy was added. This therapy was in accordance to accelerated radiotherapy reports with a final boost and concomitant chemotherapy (Reguart et al, 2004).

\section{Treatment evaluation}

Tumour response was evaluated separately following induction chemotherapy and radiochemotherapy. Patients received computed tomography (CT) scans of the chest and upper abdomen, bone scans, or in the majority of cases whole-body positron emission tomography-CT scans, and brain imaging (magnetic resonance imaging in the majority of cases) before induction chemotherapy and CT-scans at least every 6 weeks during treatment following standard procedures. Response to chemotherapy and radiochemotherapy was quantified according to RECIST (Response Evaluation Criteria in Solid Tumours) version 1.1 (Eisenhauer et al, 2009).

\section{Establishment and validation of a $\beta \mathrm{V}$-tubulin assay}

Transfections Hemagglutinine (HA)-tagged $\beta \mathrm{I}-/ \beta \mathrm{III}-/ \beta \mathrm{V}$-tubulin cDNAs subcloned into pTOPneo expression plasmids under the control of a CMV promoter were kindly provided by Fernando R. Cabral (Department of Integrative Biology and Pharmacology, The University of Texas Medical School, Houston, TX, USA): pTOP HAbI (6663 bp; GenBank accession no. U08342.1), pTOP HAbIII (6583 bp; GenBank accession no. BC031357.1), and pTOP HAbV (7007 bp; GenBank accession no. BC008225 (Blade et al, 1999; Bhattacharya and Cabral, 2004). HEK293T cells were obtained from the German Collection of Microorganisms and Cell Cultures and were cultured in DMEM medium supplemented with $10 \%$ fetal bovine serum (FBS, Coelbe, Germany), L-glutamine, penicillin and streptomycin (Invitrogen, Darmstadt, Germany) at $37^{\circ} \mathrm{C}$, in a $5 \%$ $\mathrm{CO}_{2}$-humidified incubator. Transient expression of $\beta$-tubulin isoforms was achieved by standard calcium phosphate transfection as described previously (Kasper et al, 2007). Transfection efficacies were estimated by parallel transfection of the plasmid pLPC-EGFP
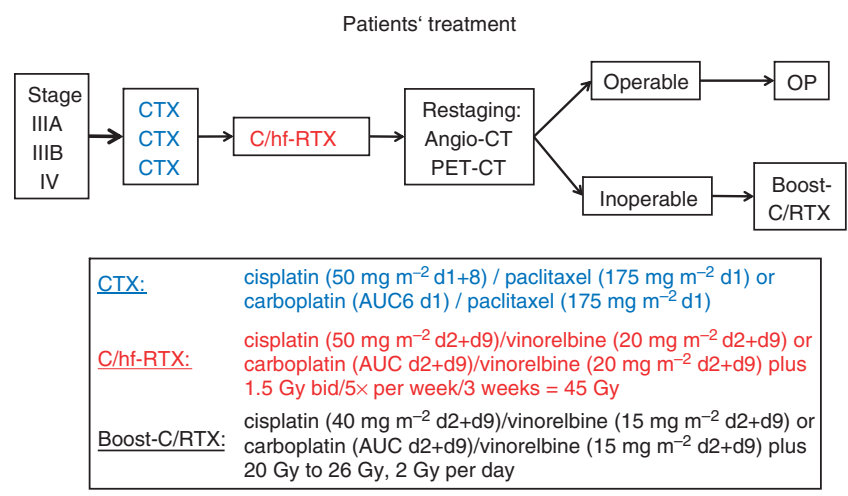

Figure I Flowchart showing the sequence of induction chemotherapy and combined radiochemotherapy, followed by surgical resection or a final boost of radiochemotherapy. Abbreviations: CTX: chemotherapy, hf: high frequency, RTX: radiotherapy. and visualisation of green fluorescent cells by microscopy (Supplementary Figure 1A).

Protein extract preparation and immunoblotting Protein lysates were prepared $48 \mathrm{~h}$ after transfection using a NP-40 containing lysis buffer as described previously (Huber et al, 2005). Immunoblotting with an anti-HA primary antibody (mouse $\mathrm{mAb}$, clone 12CA5, Roche Diagnostics, Mannheim, Germany) was performed as described previously (Kasper et al, 2007).

Immunocytochemistry/IHC of transgenic control cells and primary tumour biopsies HEK293T cells transfected to express the $\beta$-tubulin isotypes I, III, and V were grown in cell culture plates until sub-confluency and harvested. A cell pellet was prepared by centrifugation, washed twice with phosphate-buffered saline (PBS, Mediatech, Manassas, VA, USA), resolved in fixating solution consisting of $50 \%$ ethanol and $50 \%$ of PBS (10\%)-buffered formalin, and fixed for a minimum of $6 \mathrm{~h}$. After fixation, the pellet was collected by centrifugation, processed, and embedded in paraffin. The resulting blocks were sectioned at $5 \mu \mathrm{m}$ thickness and mounted on Plus GOLD slides (Fisher Scientific, Schwerte, Germany).

Sections of formalin-fixed paraffin-embedded blocks of NSCLC tumour samples and transgenic control cell pellets were deparaffinised in xylene, dehydrated in a graded ethanol series, and incubated with blocking solution (Peroxid Block, Zytomed Systems, Berlin, Germany). Antigens were retrieved by heating samples in sodium citrate buffer, $\mathrm{pH} 6.0$, for $20 \mathrm{~min}$, and the following primary antibodies were used (Supplementary Figure 2): anti-HA antibody (mouse $\mathrm{mAb}$, clone 6E2, Cell Signaling Technology, Danvers, MA, USA), anti- $\beta$ III-tubulin (mouse mAb, clone TU-20, Zytomed Systems), and anti- $\beta \mathrm{V}$-tubulin (mouse $\mathrm{mAb}$, clone 87CT59.3.7, Abgent, San Diego, CA, USA). Specific staining was detected using horseradish peroxidase (HRP)-labelled rabbit anti-mouse antibody (ZytoChemPlus (HRP) Polymer Kit, Zytomed Systems) and a 3,3'-diaminbenzidine (DAB) substrate system (DAB Substrate Kit, Zytomed Systems). Slides were counterstained with hematoxylin. Negative controls were performed by omitting the primary antibody. Furthermore, we used a brain metastasis containing a regular cortex with both neurons and glia cells, which was resected from a patient with a squamous cell carcinoma of the lung, for another set of positive and negative controls (Supplementary Figures 3A-C). Non-small cell lung cancer resection specimens having pleural nerves or nerve fascicles served as internal positive controls (Supplementary Figures 3D-F).

Immunohistochemistry evaluations were performed independently by one pathologist (JW) and one trained reader (DCC) who were blinded to the clinical data. Cytoplasmic immunoreactivity levels in each section were assessed under a light microscope and images were captured at 400 -fold magnification. Tumour staining intensity was graded on a scale from $0+$ to $3+$ and each intensity category was scored a percentage of tumour cells ranging from 0 to 100 so that the sum of the percentages adds up to 100 . The percentage score was then multiplied by its intensity category to obtain a final ' $H$-score', ranging from 0 to 300 . Ambiguous cases were reevaluated jointly until a consensus was reached.

\section{Statistical methods}

The objective of this study was to assess the association of two selected biomarkers ( $\beta$ III- and $\beta \mathrm{V}$-tubulin) with treatment response and outcome of patients with locally advanced or oligometastatic NSCLC. For metric variables, such as age and biomarker expression scores, Spearman's rank correlation coefficients were computed (Spearman, 2010). Associations between biomarker expression scores and patients' clinicopathological data were assessed using the Kruskal-Wallis test or Wilcoxon ranked sum test (test is equivalent to Kruskal-Wallis test when comparing 
two groups). For efficacy analyses, the population was divided into two groups according to median $H$-score value of the respective marker and this cutoff value was a priori chosen.

The accuracy of $\beta \mathrm{III}$ - and $\beta \mathrm{V}$-tubulin protein levels to distinguish between patients with response and non-response to paclitaxel-based treatment was evaluated by means of descriptive statistics and receiver operating characteristics (ROC) curves (Fawcett, 2004). When a significant $P$-value was found, ROC curves were computed to find an adequate threshold value for which the trade-off among sensitivity and specificity was acceptable.

PFS was calculated from the first day of induction chemotherapy until progression or the last visit when a patient was alive without progression. Overall survival was defined as the time between the start of chemotherapy until the date of death, or last follow-up. Patients were censored at last follow-up if still alive or lost to follow-up. Surveillance of PFS and OS was stopped on 15 August of 2011. Survival analysis was performed by calculating KaplanMeier curves and the significance was verified by log-rank tests. Univariate and multivariate analyses of survival were carried out using the Cox proportional hazard model, with hazard ratios (HRs) with $95 \%$ confidence interval (CI) being calculated alongside. Decrements or increments of 30 units of the $H$-score (which refer to changes in the $H$-score of units of $10 \%$ ) were used when $\beta$-tubulin levels were included as continuous variables in the Cox regression model (Lin and Ying, 1993). Cox regression analysis neither included stage nor surgical procedure because of low patient numbers (40 patients underwent resection). The level of significance was set at $\alpha=0.05$ for each evaluation. Nevertheless, as this is a retrospective study all $P$-values or results of statistical tests should be regarded as exploratory. All analyses were performed using GraphPad Prism (Version 5.00 for Windows, GraphPad Software, San Diego, CA, USA) or SAS (Version 9.2, SAS Institute Inc., Cary, NC, USA) software.

\section{RESULTS}

\section{Validation of a primary antibody against $\beta \mathrm{V}$-tubulin for IHC}

We used transgenically expressed murine $\beta \mathrm{V}$-tubulin in HEK293T cells as positive control for the validation of several primary antibodies. To positively control for transgene expression, we applied HA-tagged $\beta \mathrm{I}-/ \beta \mathrm{III}-/ \beta \mathrm{V}$-tubulin expression plasmids. Transfection efficacies in HEK293T cells ranged from 50 to $80 \%$ (Supplementary Figure 1A). Immunoblotting and IHC with an anti-HA primary antibody demonstrated successful transgene expression (Supplementary Figures 1C and 2A-D). Specific expression of $\beta$ III-tubulin was confirmed using an anti- $\beta$ IIItubulin antibody (Supplementary Figures 2E-H). Low expression of $\beta \mathrm{V}$-tubulin was found in all cells, but overexpression of $\beta$ V-tubulin was only seen in cells transfected with pTOP HAbV (Supplementary Figures 2I-L).

Immunohistochemistry was tested in a brain metastasis from a squamous cell carcinoma of the lung that was surrounded by a regular cortex with both neurons and glia cells (Supplementary Figures 3A-C). Neurons stained strongly (Supplementary Figure $3 \mathrm{~B}$ ), if the anti- $\beta$ III-tubulin antibody was used, whereas glia and squamous cell carcinoma cells stained negatively. In contrast, $\beta \mathrm{V}$-tubulin expression was detected almost exclusively in glia and tumour cells (Supplementary Figure 3C). Furthermore, in some tumour samples we observed an inversely proportional expression tubulin pattern (low $\beta \mathrm{III} /$ high $\beta \mathrm{V}$ ) (Supplementary Figures 3G-I).

\section{Association between $\beta \mathrm{III}-/ \beta \mathrm{V}$-tubulin expression and clinicopathological data}

Cytoplasmatic expression of $\beta \mathrm{III}$ - and $\beta \mathrm{V}$-tubulin in tumour cells was assessed by IHC and quantitated. Examples of different expression levels of $\beta \mathrm{III}$ - or $\beta \mathrm{V}$-tubulin are depicted in Figure 2. Median $H$-scores were 110 (range: 0-290) for $\beta$ III-tubulin, and 160 (range: $0-290$ ) for $\beta \mathrm{V}$-tubulin (Supplementary Figure $4 \mathrm{~A}$ ). At univariate analyses, no significant association between $\beta$ III-tubulin expression and age, gender, primary tumour location, histological grade or subtype, or IASLC stage was found (Table 2). Furthermore, no correlation was observed between $\beta \mathrm{V}$-tubulin expression and age, gender, primary tumour location, or histological grade (Table 2). A borderline significant association between histological subtypes and $\beta \mathrm{V}$-tubulin expression was seen $\left(P_{\mathrm{KW}}=0.0704\right)$. Squamous cell carcinomas expressed significantly higher $\beta \mathrm{V}$ tubulin levels as compared with non-squamous cell carcinomas (mean $H$-score of $178 \pm 11$, median 187.5 vs mean $141 \pm 9$, median $150 ; P=0.0271)$. Furthermore, an association between clinicopathological stage and $\beta \mathrm{V}$-tubulin expression was observed $\left(P_{\mathrm{KW}}=0.0097\right)$, if IASLC stages IIIA, IIIB, and IV were compared. $\alpha: \beta$ III-tubulin $1: 200$

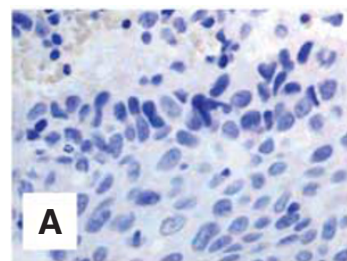

$\alpha: \beta$ V-tubulin $1: 5000$

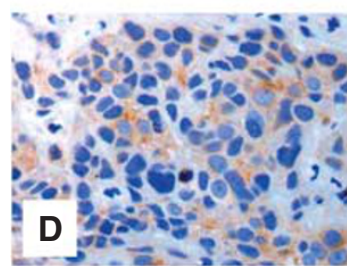

$\alpha: \beta$ III-tubulin 1:200

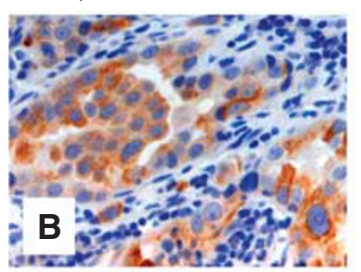

$\alpha: \beta \bigvee$-tubulin $1: 5000$

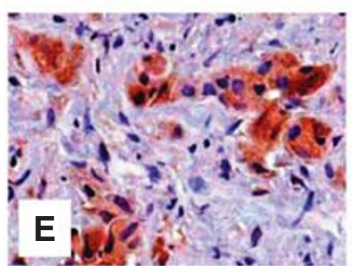

$\alpha: \beta$ III-tubulin 1:200

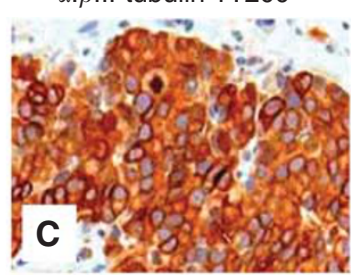

$\alpha: \beta$ V-tubulin $1: 5000$

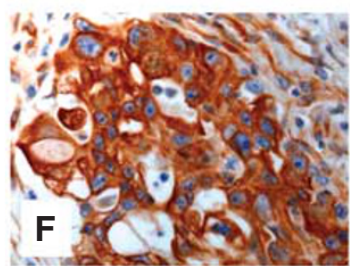

Figure 2 Examples of $\mathrm{HC}$ for the $\beta \| \mathrm{I}$ - or $\beta \bigvee$-tubulin isotypes in NSCLC samples showing different protein expressions of the regarding isotype. Upper panel: $\| \mathrm{HC}$ with an antibody against $\beta$ III-tubulin. $(\mathbf{A})$ A negatively stained NSCLC sample $(H$-score of 0$)$, (B) a moderately stained NSCLC sample $(H$-score of I80), and (C) a strongly stained NSCLC sample (H-score of 290); lower panel: IHC with an antibody against $\beta \bigvee$-tubulin. (D) A weakly stained NSCLC sample (H-score of 50), (E) a moderately stained NSCLC sample (H-score of I60), and (F) a strongly stained NSCLC sample (H-score of 290). Magnification: I : 100. 


\begin{tabular}{|c|c|c|c|c|c|c|}
\hline & \multicolumn{3}{|c|}{ (A) $\beta$ III-tubulin } & \multicolumn{3}{|c|}{ (B) $\beta V$-tubulin } \\
\hline & $\begin{array}{c}\text { No. of } \\
\text { patients }\end{array}$ & $\begin{array}{c}H \text {-score } \\
\text { (mean } \pm \text { s.e.m., median) }\end{array}$ & & $\begin{array}{c}\text { No. of } \\
\text { patients }\end{array}$ & $\begin{array}{c}\text { H-score } \\
\text { (mean } \pm \text { s.e.m., median) }\end{array}$ & \\
\hline \multicolumn{7}{|l|}{ Histology } \\
\hline $\begin{array}{l}\text { Adenocarcinoma } \\
\text { Squamous cell carcinoma } \\
\text { Other carcinomas }\end{array}$ & $\begin{array}{l}29 \\
16 \\
20\end{array}$ & $\begin{array}{l}122 \pm 13,110 \\
101 \pm 20,105 \\
121 \pm 16,107.5\end{array}$ & $P_{\mathrm{kW}}=0.6224$ & $\begin{array}{l}29 \\
16 \\
20\end{array}$ & $\begin{array}{l}137 \pm 12,150 \\
178 \pm 11,187.5 \\
147 \pm 15,155\end{array}$ & $P_{\mathrm{KW}}=0.0704$ \\
\hline \multicolumn{7}{|l|}{ Histology } \\
\hline Adenocarcinoma & 29 & & $P=0.4838$ & 29 & & $P=0.0960$ \\
\hline $\begin{array}{l}\text { Other carcinomas } \\
\text { Squamous cell carcinoma }\end{array}$ & $\begin{array}{l}36 \\
16\end{array}$ & $\begin{array}{l}112 \pm 12,107.5 \\
101 \pm 122,105\end{array}$ & $P=0.3524$ & $\begin{array}{l}36 \\
16\end{array}$ & $\begin{array}{l}161 \pm 10,175 \\
178 \pm 11,187.5\end{array}$ & $P=0.0271$ \\
\hline Other carcinomas & 49 & $122 \pm 10,110$ & & 49 & $14 \mid \pm 9,150$ & \\
\hline \multicolumn{7}{|l|}{ Histological grade } \\
\hline $\mathrm{G} 2$ & 19 & $132 \pm 17,120$ & $P_{\mathrm{KW}}=0.4564$ & 19 & $162 \pm 15,170$ & $P_{\mathrm{KW}}=0.5283$ \\
\hline G3 & 44 & $110 \pm 11,102.5$ & & 44 & $148 \pm 9,155$ & \\
\hline G4 & 2 & $125 \pm 15,125$ & & 2 & $105 \pm 95,105$ & \\
\hline \multicolumn{7}{|l|}{ Gender } \\
\hline Female & 21 & $129 \pm 18,110$ & $P=0.2988$ & 21 & $|5| \pm \mid 4,180$ & $P=0.4693$ \\
\hline Male & 44 & $111 \pm 10,105$ & & 44 & $150 \pm 9,157.5$ & \\
\hline \multicolumn{7}{|l|}{ Side } \\
\hline Left & 24 & $120 \pm 15,107.5$ & $P=0.8277$ & 24 & $147 \pm 14,167.5$ & $P=0.8918$ \\
\hline Right & 41 & $115 \pm 11,110$ & & 41 & $152 \pm 9,155$ & \\
\hline \multicolumn{7}{|l|}{ Stage } \\
\hline IASLC IIIA & 23 & $99 \pm 15,80$ & $P_{\mathrm{KW}}=0.1348$ & 23 & $157 \pm 11,170$ & $P_{\mathrm{KW}}=0.0097$ \\
\hline IASLC IIIB & 29 & $132 \pm 12,120$ & & 29 & $167 \pm 12,180$ & \\
\hline IASLC IV & 10 & $119 \pm 29,102.5$ & & 10 & $99 \pm 18,105$ & \\
\hline \multicolumn{7}{|l|}{ Stage } \\
\hline |ASLC ||| & 52 & $117 \pm 10,110$ & $P=0.8631$ & 52 & $163 \pm 8,172.5$ & $P=0.0030$ \\
\hline IASLC IV & 10 & $119 \pm 29,102.5$ & & 10 & $99 \pm 18,105$ & \\
\hline
\end{tabular}

Abbreviation: $\mid A S L C=$ International Association for the Study of Lung Cancer. Association between (A) $\beta \| l \mid$-tubulin or (B) $\beta$ V-tubulin protein expression and clinicopathological data.

Table 3 Associations between objective response (OR) or disease control (DC) during induction chemotherapy and (A) $\beta \| l$-tubulin or (B) $\beta \vee$-tubulin protein expression

\begin{tabular}{|c|c|c|c|c|c|c|}
\hline & \multicolumn{3}{|c|}{ (A) $\beta$ III-tubulin } & \multicolumn{3}{|c|}{ (B) $\beta$ V-tubulin } \\
\hline $\begin{array}{l}C R+P R \\
S D+P D\end{array}$ & $\begin{array}{l}46 \\
19\end{array}$ & $\begin{array}{l}119 \pm 11,110 \\
111 \pm 15,105\end{array}$ & & $\begin{array}{l}46 \\
19\end{array}$ & $\begin{array}{l}163 \pm 9,172.5 \\
121 \pm 13,120\end{array}$ & \\
\hline
\end{tabular}

Abbreviations: $C R=$ complete remission; $\mathrm{PD}=$ progressive disease; $\mathrm{PR}=$ partial remission; $\mathrm{SD}=$ stable disease.

Stage III was associated with higher expression levels of $\beta$ V-tubulin (mean $H$-score of $163 \pm 8$, median 172.5) compared with stage IV (mean $H$-score of $99 \pm 18$, median $105 ; P=0.0030$ ).

\section{Intratumoural correlation of $\beta$ III- or $\beta \mathrm{V}$-tubulin expression}

In the entire cohort of patients a weak, but statistically significant correlation between $\beta \mathrm{III}$ - and $\beta \mathrm{V}$-tubulin expression was seen $(r=0.3561, P=0.0036$; Supplementary Figure $4 \mathrm{~B})$. Further, we tested whether gender might influence the intratumoural $\beta \mathrm{III}-/ \beta \mathrm{V}$ tubulin-correlation. We observed a weak, but significant, correlation in males $(r=0.3081, P=0.0419$; Supplementary Figure $4 \mathrm{D})$, but not in females.

\section{Association of $\beta \mathrm{III}$ - or $\beta \mathrm{V}$-tubulin expression with response to induction chemotherapy}

We discovered an association between high $\beta \mathrm{V}$-tubulin expression (Table 3) and improved OR (mean $H$-score of $163 \pm 9$, median 172.5 for $\mathrm{CR}+\mathrm{PR}$ vs $121 \pm 13$, median 120 for $\mathrm{SD}+\mathrm{PD}$, $P=0.0104)$. Similarly, high $\beta \mathrm{V}$-tubulin levels were associated with better disease control (DC) (mean $H$-score of $158 \pm 8$, median 170 for $\mathrm{CR}+\mathrm{PR}+\mathrm{SD}$ vs $91 \pm 22$, median 100 for $\mathrm{PD}, P=0.0081)$. There were no significant associations between $\beta$ III-tubulin expression and OR or DC to induction chemotherapy (Table 3). Neither $\beta$ III- nor $\beta$ V-tubulin levels were associated with OR or DC to radiochemotherapy (data not shown).

As we observed a significant association between high $\beta \mathrm{V}$ tubulin protein levels and OR or DC, we calculated ROC curves 
revealing area under-the-curve (AUC) values of 0.7037 and 0.8091 for OR and DC, respectively. Therefore, we further estimated the sensitivity, specificity, positive and negative predictive value for $\beta \mathrm{V}$-tubulin protein levels and OR, which were $74,57,54$, and $84 \%$ by using a cutoff value of 167.5, respectively (Supplementary Table 1). Using a cutoff value of 135 for $\beta \mathrm{V}$-tubulin protein levels and DC, the values were $86,66,71$, and $92 \%$ for sensitivity, specificity, positive and negative predictive value, respectively.

\section{Association between $\beta \mathrm{III}$ - or $\beta \mathrm{V}$-tubulin expression and survival}

Assessing the impact of tumour stages IIIA, IIIB, and IV on survival, we found a significant $(P \leqslant 0.001)$ association of tumour stage with PFS (median PFS stage IIIA: 19.2 months; IIIB: 15.2 months; and IV: 6.1 months). A borderline significant association of tumour stage and OS was observed $(P=0.0761$; median OS stage IIIA: $\geqslant 36.1$ months; IIIB: 59.3 months; and IV: 29.4 months).

At univariate analyses, $\beta$ III-tubulin expression was associated with OS, but not with PFS (Figures $3 \mathrm{~A}$ and $\mathrm{B}$ ). Using the median $H$-scores as cutoff value, we found an association between favourable OS (Figure 3B) and low $\beta$ III-tubulin protein expression (median OS 68.0 months vs 25.9 months in low $v s$ high $\beta$ III-tubulin expressors; HR: 0.328 , 95\% CI: 0.131 to 0.821 ; $P=0.0127$ ). High $\beta$ V-tubulin expression was associated with prolonged PFS (median PFS 19.2 months vs 9.4 months for high $v s$ low $\beta$ V-tubulin expressors; HR: $1.899,95 \%$ CI: $1.048-3.439 ; P=0.0315)$, but not with OS (Figures $3 \mathrm{C}$ and $\mathrm{D}$ ). The association between $\mathrm{OS}$ and $\beta$ III-tubulin expression remained significant when adjusting for histology (HR for 30 units of decrement or increment in $\beta$ III-tubulin: 1.348 (95\% CI: $\left.1.106-1.641), P_{\mathrm{COX}}=0.0028\right)$ or both histology and $\beta \mathrm{V}$-tubulin (HR for 30 units of decrement or increment in $\beta$ III-tubulin: 1.411 (95\% CI: $1.153-1.734)$, $\left.P_{\mathrm{COX}}=0.0009\right)$. Interaction terms where included as well, but they turned out nonsignificant that may also be due to small
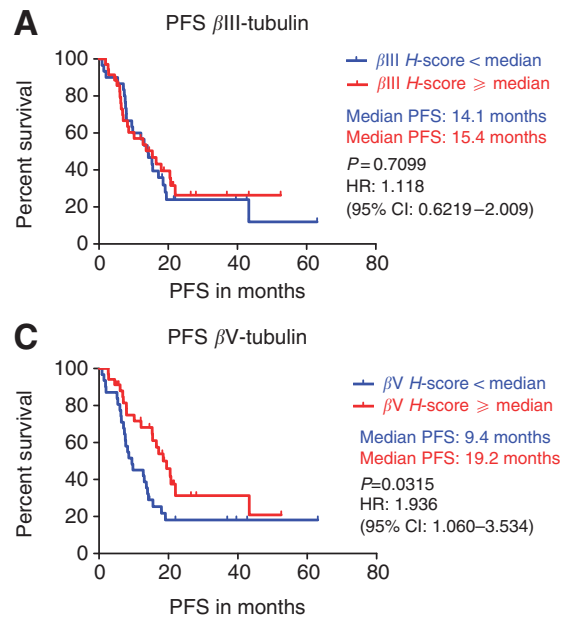

E PFS combined $\beta$ III- and $\beta \mathrm{V}$-tubulin expression

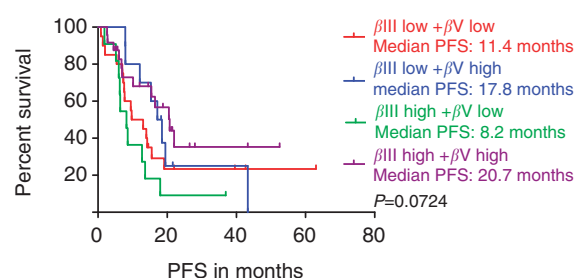

sample size. The same was true for the association between $\beta \mathrm{V}$ tubulin and PFS observed at univariate analysis, which remained significant, when adjusting for histology (HR for 30 units of decrement or increment in $\beta \mathrm{V}$-tubulin: $0.798(95 \% \mathrm{CI}$ : $\left.0.677-0.938), P_{\mathrm{COX}}=0.0053\right)$. However, significance was lost when adjusting for histology and $\beta$ III-tubulin expression (HR for 30 units of decrement or increment in $\beta \mathrm{V}$-tubulin: 0.864 (95\% CI: $\left.0.690-1.081), P_{\mathrm{COX}}=0.1938\right)$. Furthermore, a significant interaction between histology and $\beta$ III-tubulin expression was observed in Cox regression modelling PFS. Computing HRs for PFS and $\beta$ III-tubulin in histologic subgroups revealed an HR for an decrease or increase of 30 units in $\beta$ III-tubulin was 1.244 (95\% CI: $\left.1.012-1.535, P_{\mathrm{COX}}=0.039\right)$ for adenocarcinomas, HR was 0.803 (95\% CI: $\left.0.591-1.087, P_{\mathrm{COX}}=0.1569\right)$ for squamous cell carcinomas, and $\mathrm{HR}$ was 0.930 (95\% CI: 0.644-1.310, $\left.P_{\mathrm{COX}}=0.6847\right)$ for all other histological subtypes.

\section{Association between combined $\beta \mathrm{III}$ - or $\beta \mathrm{V}$-tubulin expression and survival}

Patients were categorised in four groups according to $\beta \mathrm{III}-/ \beta \mathrm{V}$ tubulin expression: low $\beta \mathrm{III} /$ low $\beta \mathrm{V}$, low $\beta \mathrm{III} /$ high $\beta \mathrm{V}$, high $\beta \mathrm{III} /$ low $\beta \mathrm{V}$, and high $\beta \mathrm{III} /$ high $\beta \mathrm{V}$ (Figures $3 \mathrm{E}$ and $\mathrm{F}$ ). Analyses of PFS and OS revealed significant differences between 'low $\beta \mathrm{III} / \mathrm{high}$ $\beta \mathrm{V}$-tubulin expressors' and 'high $\beta \mathrm{III} /$ low $\beta \mathrm{V}$-tubulin expressors' in PFS $(P=0.0472)$ and OS $(P=0.0012)$. Furthermore, patients with tumours expressing low $\beta$ III- and high $\beta$ V-tubulin levels had the longest OS (43.3 months), whereas patients whose tumours expressed high $\beta \mathrm{III}$ - and low $\beta \mathrm{V}$-tubulin levels had the shortest OS (16.7 months).

\section{DISCUSSION}

Current medical treatment of advanced NSCLC patients still largely relies on classical cytotoxic agents. Tubulin-binding agents such as
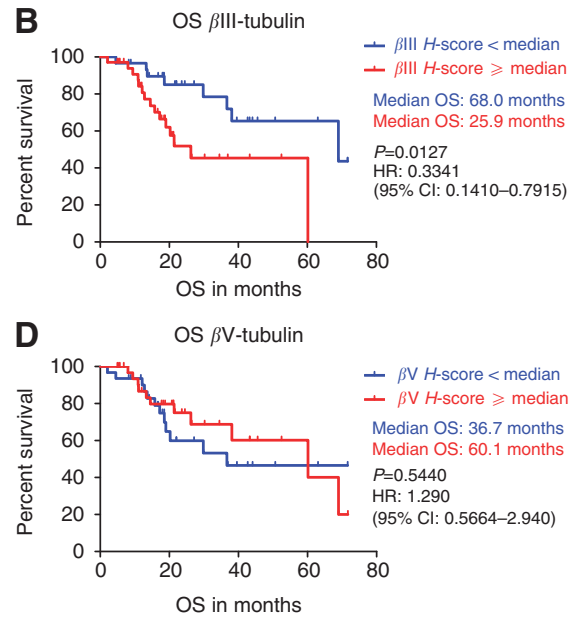

F OS combined $\beta I I I-$ and $\beta \mathrm{V}$-tubulin expression

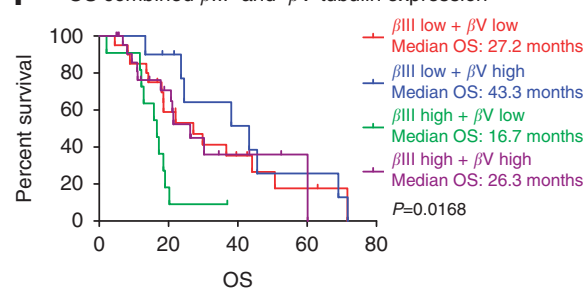

Figure 3 Associations between $\beta$ III- or $\beta \bigvee$-tubulin protein expression and progression-free survival (PFS) or overall survival (OS). Associations between $\beta$ III-tubulin expression and PFS $(\mathbf{A})$ or OS $(\mathbf{B})$, between $\beta \bigvee$-tubulin expression and PFS $(\mathbf{C})$ or OS $(\mathbf{D})$ or between combined expression of $\beta$ III-/ $\beta \bigvee$-tubulin and PFS (E) or OS (F). Patients were categorised by the median $H$-scores of $\beta \mid l$-tubulin (I I 0) or $\beta \bigvee$-tubulin ( I 60). 
taxanes and Vinca alkaloids are effective as combination partners of platinum compounds, as well as in palliative monotherapy of relapsing or comorbid patients (Felip et al, 2011). Moreover, TBAs are used as radiosensitisers in concurrent radiochemotherapy protocols (Azuma et al, 2009a). Several agents that have recently been introduced into treatment of metastatic NSCLC are selected based on established biomarkers. Key examples are 'non-squamous' histology for bevacizumab and pemetrexed, somatic EGFR mutations for erlotinib and gefitinib, and most recently $A L K$ translocations for crizotinib (Felip et al, 2011). In contrast, the selection of TBAs is still entirely based on clinical considerations. Although TBAs have clearly established efficacy in NSCLC, they are also associated with considerable toxicities including hematotoxicity, neurotoxicity, mucositis and alopecia. Hence, the definition of biomarkers for guidance of therapeutic application of TBAs would be of high clinical relevance.

Therefore, we have rationally selected immunohistochemically detectable intratumoural expression of $\beta$-tubulin isotypes for an association study with clinical outcome in a cohort of locally advanced and oligometastatic NSCLC patients. We focused on $\beta$-tubulins as they were implied in resistance to taxanes in various cancer cells (Orr et al, 2003). Moreover, the level of $\beta$ III-tubulin expression was reported to correlate with OR and PFS in retrospective analyses of NSCLC patients treated with paclitaxelbased regimens. As these studies did not provide conclusive results (Rosell et al, 2003; Dumontet et al, 2005; Seve et al, 2005; Okuda et al, 2008; Azuma et al, 2009b; Kang et al, 2009; Zalcman et al, 2009; Kang et al, 2010), we reasoned that combined expression analysis of the structurally similar isotypes $\beta \mathrm{III}-$ and $\beta \mathrm{V}$-tubulin might provide a more comprehensive picture. At the initiation of our study an anti- $\beta$ III-tubulin antibody, but no anti- $\beta \mathrm{V}$-tubulin antibody was available for IHC of formalin-fixed paraffinembedded tumour samples. Accordingly, we devised several positive and negative controls to establish and validate sensitivity and specificity of a commercially available anti- $\beta \mathrm{V}$-tubulin antibody for this type of analysis.

Applying those two validated primary antibodies, we analysed tumour samples from 65 patients suffering from stage III or oligometastatic stage IV NSCLC. Despite being moderately sized, patients were treated uniformly with paclitaxel-based induction chemotherapy and vinorelbine-based radiochemotherapy, which enabled a meaningful analysis of the clinical interaction of $\beta$-tubulin expression and clinical outcome. However, a subgroup of 40 patients underwent surgery, whereas the remaining patients received a final boost of radiochemotherapy. We were able to observe for the first time that high expression of $\beta \mathrm{V}$-tubulin was significantly associated with improved OR after paclitaxel-based induction chemotherapy and prolonged PFS. In keeping with previous reports also including perioperatively treated patients, an association of low $\beta$ III-tubulin expression with improved OS (Seve et al, 2005; Okuda et al, 2008; Zalcman et al, 2009; Kang et al, 2010) was found in our cohort, but not with OR (Dumontet et al, 2005; Azuma et al, 2009a) or PFS (Rosell et al, 2003; Azuma et al, 2009a; Kang et al, 2009). Although high expression of $\beta \mathrm{V}$-tubulin was associated with squamous cell carcinomas, the positive correlation with PFS was maintained when adjusting for histology at regression analysis. Interestingly, $\beta \mathrm{III}-$ or $\beta \mathrm{V}$-tubulin staining failed to correlate with $\mathrm{OR}$ to vinorelbine-based concurrent radiochemotherapy. Within the limitations of the size of our cohort, we suggest that a potential predictive value of $\beta \mathrm{V}$-tubulin expression either is confined to taxanes or is confounded when TBAs are concurrently administered with radiation.

Surprisingly, high $\beta \mathrm{V}$-tubulin levels were associated with better $\mathrm{OR}$ and prolonged PFS, but not lower levels. In vitro studies reported that murine $\beta \mathrm{V}$-tubulin increased tolerance for paclitaxel in human cancer cells (Bhattacharya and Cabral, 2004) and might confer paclitaxel resistance (Bhattacharya and Cabral, 2009). But human $\beta \mathrm{V}$-tubulin binds paclitaxel with a higher affinity than murine $\beta \mathrm{V}$-tubulin does (Verdier-Pinard et al, 2005). Furthermore, microtubules in mammalian cells depleted of $\beta \mathrm{V}$-tubulin are more stable than normal. These cells have a reduced mitotic progression and might be less sensitive for polymerising paclitaxel (Bhattacharya et al, 2008). But cells with a high expression of $\beta \mathrm{V}$-tubulin have very low levels of polymerised $\beta \mathrm{V}$-tubulin (Bhattacharya et al, 2011). Therefore, overexpression of human $\beta \mathrm{V}$-tubulin might increase sensitivity to paclitaxel. Additionally, a highly regulated balance between $\beta \mathrm{III}-$ and $\beta \mathrm{V}$-tubulin occurs in cells, and the combined expression of $\beta \mathrm{III}-$ and $\beta \mathrm{V}$-tubulin may not exceed $\sim 20 \%$ of the total $\beta$-tubulin (Verdier-Pinard et al, 2005) for normal cell function. As $\beta$ III- and $\beta$ V-tubulin are expressed in a complementary pattern at the protein level, human cancer cells expressing $\beta \mathrm{V}$-tubulin at higher levels might suppress $\beta$ III-tubulin expression and be more paclitaxel sensitive.

There are several limitations in our study. First, this is a retrospective study. Only patients with available pre-treatment tumour samples were included in our study. Second, as patients with high $\beta$ V-tubulin expression achieved a better mean OR to induction chemotherapy $(P=0.0104)$, this might have resulted in skewing of the application of surgical procedures towards that subgroup. Third, significant associations between PFS/OS and protein levels of $\beta$ III-tubulin were recently found in pulmonary adenocarcinoma patients, but not in squamous cell carcinomas (Vilmar et al, 2011). Gender also influences the $\beta \mathrm{III}-/ \beta \mathrm{V}$-tubulin ability to predict poor outcome in colorectal cancer (Mariani et al, 2012). But the patient number in our study was too low to perform meaningful subgroup analyses for adenocarcinoma or female patients. Fourth, although the induction chemotherapy and combined radiochemotherapy were uniform, the patient cohort is heterogenous. We will evaluate the predictive value of $\beta \mathrm{III}-/ \beta \mathrm{V}$ tubulin expression within a prospective phase III clinical trial. This trial compares a final boost of radiochemotherapy to surgical resection as part of the multimodality treatment and is balanced for stage IIIA/B patients. Furthermore, we will explore the prognostic value of $\beta \mathrm{III}-/ \beta \mathrm{V}$-tubulin expression in a cohort of IASLC stage I patients who were exclusively treated by surgery.

In conclusion, we have established semiquantitative immunohistochemical detection of $\beta \mathrm{V}$-tubulin as a putative biomarker to predict outcome of advanced NSCLC patients following taxanebased chemotherapy. Combined analysis of $\beta \mathrm{III}-$ and $\beta \mathrm{V}$-tubulin expression may provide more robust prognostic and/or predictive information. On the basis of these results and the validated suitability of our $\beta \mathrm{V}$-tubulin staining protocol, prospective studies of these promising biomarkers in NSCLC patients treated with TBAs are warranted.

\section{ACKNOWLEDGEMENTS}

We thank D Luetke-Brintrup, I Perelmuter, S Fox, and R Daniels for supporting clinical data collection, G Ladwig, B Linker, S Schaefer, R Kern, D Gerecke, M Schroeder, and L Ellenberg for their technical assistance, as well as J Eckelberger for critically reading the manuscript. This work was supported by an IASLC Fellowship Award (DCC).

\section{Conflict of interest}

The authors declare no conflict of interest.

Supplementary Information accompanies the paper on British Journal of Cancer website (http://www.nature.com/bjc) 


\section{REFERENCES}

Azuma K, Sasada T, Kawahara A, Hattori S, Kinoshita T, Takamori S, Ichiki M, Imamura Y, Ikeda J, Kage M., Kuwano M, Aizawa H (2009a) Expression of ERCC1 and class III beta-tubulin in non-small cell lung cancer patients treated with a combination of cisplatin/docetaxel and concurrent thoracic irradiation. Cancer Chemother Pharmacol 64: 565-573

Azuma K, Sasada T, Kawahara A, Takamori S, Hattori S, Ikeda J, Itoh K, Yamada A, Kage M, Kuwano M, Aizawa H (2009b) Expression of ERCC1 and class III beta-tubulin in non-small cell lung cancer patients treated with carboplatin and paclitaxel. Lung Cancer 64: 326-333

Banerjee A, Jensen-Smith H, Lazzell A, Prasad V, Elguezabal G, Hallworth Richard, Luduena RF (2008) Localization of betav tubulin in the cochlea and cultured cells with a novel monoclonal antibody. Cell Motil Cytoskeleton 65: 505-514

Bhattacharya R, Cabral F (2004) A ubiquitous beta-tubulin disrupts microtubule assembly and inhibits cell proliferation. Mol Biol Cell 15: 3123-3131

Bhattacharya R, Cabral F (2009) Molecular basis for class V beta-tubulin effects on microtubule assembly and paclitaxel resistance. $J$ Biol Chem 284: 13023-13032

Bhattacharya R, Frankfurter A, Cabral F (2008) A minor beta-tubulin essential for mammalian cell proliferation. Cell Motil Cytoskeleton 65: 708-720

Bhattacharya R, Yang H, Cabral F (2011) Class V $\beta$-tubulin alters dynamic instability and stimulates microtubule detachment from centrosomes. Mol Biol Cell 22: 1025-1034

Blade K, Menick DR, Cabral F (1999) Overexpression of class I, II or IVb beta-tubulin isotypes in $\mathrm{CHO}$ cells is insufficient to confer resistance to paclitaxel. J Cell Sci 113: 2213-2221

Detterbeck FC, Boffa DJ, Tanoue LT (2009) The new lung cancer staging system. Chest 136: 260-271

Dumontet C, Isaac S, Souquet P-J, Bejui-Thivolet F, Pacheco Y, Peloux N, Frankfurter A, Luduena R, Perol M (2005) Expression of class III beta tubulin in non-small cell lung cancer is correlated with resistance to taxane chemotherapy. Bull Cancer 92: E25-E30

Eisenhauer EA, Therasse P, Bogaerts J, Schwartz LH, Sargent D, Ford R, Dancey J, Arbuck S, Gwyther S, Mooney M, Rubinstein L, Shankar L, Dodd L, Kaplan R, Lacombe D, Verweij J (2009) New response evaluation criteria in solid tumours: revised RECIST guideline (version 1.1). Eur J Cancer 45: 228-247

Fawcett T (2004) ROC graphs: notes and practical considerations for researchers. ReCALL 31: 1-38

Felip E, Gridelli C, Baas P, Rosell R, Stahel R, Panel Members (2011) Metastatic non-small-cell lung cancer: consensus on pathology and molecular tests, first-line, second-line, and third-line therapy: 1st ESMO. Consensus Conference in Lung Cancer. Ann Oncol 22: 1507-1519

Felip E, Vilar E (2006) The expanding role of systemic treatment in non-small cell lung cancer neo-adjuvant therapy. Ann Oncol 17: $\mathrm{x} 108-\mathrm{x} 112$

Hari M, Yang H, Zeng C, Canizales M, Cabral F (2003) Expression of class III beta-tubulin reduces microtubule assembly and confers resistance to paclitaxel. Cell Motil Cytoskeleton 56: 45-56

Hiser L, Aggarwal A, Young R, Frankfurter A, Spano A, Correira JJ, Lobert $S$ (2006) Comparison of beta-tubulin mRNA and protein levels in 12 human cancer cell lines. Cell Motil Cytoskeleton 63: 41-52

Huber C, Bobek N, Kuball J, Thaler S, Hoffarth S, Huber C, Theobald M, Schuler M (2005) Inhibitors of apoptosis confer resistance to tumour suppression by adoptively transplanted cytotoxic T-lymphocytes in vitro and in vivo. Cell Death Differ 12: 317-325

Jordan MA (2002) Mechanism of action of antitumor drugs that interact with microtubules and tubulin. Curr Med Chem Anticancer Agents 2: 1-17
Jordan MA, Wilson L (2004) Microtubules as a target for anticancer drugs Nat Rev Cancer 4: 253-265

Kamath K, Wilson L, Cabral F, Jordan MA (2005) BetaIII-tubulin induces paclitaxel resistance in association with reduced effects on microtubule dynamic instability. J Biol Chem 280: 12902-12907

Kang CH, Jang BG, Kim D-W, Chung DH, Kim YT, Jheon S, Sung S-W, Kim JH (2009) Differences in the expression profiles of excision repair crosscomplementation group 1, x-ray repair crosscomplementation group 1, and betaIII-tubulin between primary non-small cell lung cancer and metastatic lymph nodes and the significance in mid-term survival. I Thorac Oncol 4: 1307-1312

Kang CH, Jang BG, Kim D-W, Chung DH, Kim YT, Jheon S, Sung S-W, Kim JH (2010) The prognostic significance of ERCC1, BRCA1, XRCC1, and betaIII-tubulin expression in patients with non-small cell lung cancer treated by platinum- and taxane-based neoadjuvant chemotherapy and surgical resection. Lung Cancer 68: 478-483

Kasper S, Kindler T, Sonnenschein S, Breitenbuecher F, Boehmer FD, Huber C, Fischer T (2007) Cross-inhibition of interferon-induced signals by GM-CSF through a block in Stat1 activation. J Interferon Cytokine Res 27: 947-959

Lin DY, Ying Z (1993) A simple nonparametric estimator of the bivariate survival function under univariate censoring. Biometrika 80: 573-581

Mariani M, Zannoni GF, Sioletic S, Sieber S, Martino C, Martinelli E, Coco C, Scambia G, Shahabi S, Ferlini C (2012) Activation of the mTOR pathway in primary medullary thyroid carcinoma and lymph node metastases. Clin Cancer Res 18: 1

Okuda K, Sasaki H, Dumontet C, Kawano O, Yukiue H, Yokoyama T, Yano M, Fujii Y (2008) Expression of excision repair cross-complementation group 1 and class III beta-tubulin predict survival after chemotherapy for completely resected non-small cell lung cancer. Lung Cancer 62: 105-112

Orr GA, Verdier-Pinard P, McDaid H, Horwitz SB (2003) Oncogene 22: 7280-7295

Reguart N, Vinolas N, Casas F, Gimferrer JM, Agusti C, Molina R, MartinRichard M, Sanchez-Reyes A, Gascon P (2004) Integrating concurrent navelbine and cisplatin to hyperfractionated radiotherapy in locally advanced non-small cell lung cancer patients treated with induction and consolidation chemotherapy: feasibility and activity results. Lung Cancer 45: $67-75$

Rosell R, Scagliotti G, Danenberg KD, Lord RVN, Bepler G, Novello S, Cooc J, Crino L, Sanchez JJ, Taron M, Boni C, De Marinis F, Tonato M, Marangalo M, Gozzelino F, Di Constanzo F, Rinaldi M, Salongo D, Stephens C (2003) Transcripts in pretreatment biopsies from a three-arm randomized trial in metastatic non-small-cell lung cancer. Oncogene 22: 3548-3553

Seve P, Mackey J, Isaac S, Tredan O, Souquet P-J, Perol M, Lai R, Voloch A, Dumontet C (2005) Class III beta-tubulin expression in tumor cells predicts response and outcome in patients with non-small cell lung cancer receiving paclitaxel. Mol Cancer Ther 4: 2001-2007

Spearman C (2010) The proof and measurement of association between two things. Int J Epidemiol 39: 1137-1150

Sullivan KF, Havercroft JC, Machlin PS, Cleveland DW (1986) Sequence and expression of the chicken beta 5 - and beta 4-tubulin genes define a pair of divergent beta-tubulins with complementary patterns of expression. Mol Cell Biol 6: 4409-4418

Verdier-Pinard P, Shahabi S, Wang F, Burd B, Xiao H, Goldberg GL, Orr GA, Horwitz SB (2005) Biochemistry 44: 15858-15870

Vilmar AC, Santoni-Rugiu E, Sorensen JB (2011) Class III $\beta$-tubulin in advanced NSCLC of adenocarcinoma subtype predicts superior outcome in a randomized trial. Clin Cancer Res 17: 5205-5214

Zalcman G, Levallet G, Bergot E, Antoine M, Creveuil C, Beau-Faller M, Brambilla E, Galateau-Salle F, Dumontet C, Morin F, Depierre A, Milleron B (2009) J Thorac Oncol 4: (abstract A 4.1)

This work is published under the standard license to publish agreement. After 12 months the work will become freely available and the license terms will switch to a Creative Commons Attribution-NonCommercial-Share Alike 3.0 Unported License. 